\title{
Correction to: Evolutionary allometry of sexual dimorphism of jumping performance in anurans
}

\author{
Bryan H. Juarez ${ }^{1}$ (D) . Dean C. Adams ${ }^{1}$ (D)
}

Published online: 18 October 2021

(c) Springer Nature Switzerland AG 2021

\section{Correction to: Evolutionary Ecology https://doi.org/10.1007/s10682-021-10132-x}

The original article was published with incomplete acknowledgment section. The complete acknowledgment section is provided in this correction.

Acknowledgements This work was supported by a National Science Foundation Graduate Research Fellowship (to BHJ), National Science Foundation Grant DBI-1902511 (to DCA), and a California Academy of Natural Sciences Michele L. Aldrich Collections Research Grant (to BHJ). We thank Andres Vargas for help with data collection, Elizabeth Glynne for helpful discussions, Anne Bronikowski, Philip Dixon, and two reviewers for useful insight. Finally, we are indebted to the many museum curators and collection managers that made this work possible including those at: the American Museum of Natural History $(\mathrm{AMNH})$; the Academy of Natural Sciences of Drexel University, Vertebrate Zoology Dept (ANSP); the Monte L. Bean Life Science Museum (MLBM) Herpetology Collection at Brigham Young University (BYU); the Department of Herpetology, California Academy of Sciences (CAS); Amphibians and Reptiles (Herpetology) at Carnegie Museum of Natural History (CM); Amphibians and Reptiles at the Field Museum of Natural History (FMNH); the Georgia Southern University-Savannah Science Museum Herpetology Collection (GSU); the Biodiversity Institute and Natural History Museum of the University of Kansas (KU); the Natural History Museum of Los Angeles County (LACM); the Museum of Comparative Zoology (MCZ); the Museum of Southwestern Biology (MSB); the Museum of Vertebrate Zoology, University of California, Berkeley (MVZ); the North Carolina Museum of Natural Sciences (NCSM); the Sam Noble Oklahoma Museum of Natural History, University of Oklahoma (OMNH); the Slater Museum of Natural History at the University of Puget Sound (PSM); the San Diego Museum of Natural History (SDNHM); the Biodiversity Research and Teaching Collections, Texas A\&M University (TCWC); the Texas Memorial Museum (TMM) and Texas Natural History Collections

The original article can be found online at https://doi.org/10.1007/s10682-021-10132-x.

Bryan H. Juarez

bryanhjuarez@gmail.com

1 Department of Ecology, Evolution, and Organismal Biology, Iowa State University, Ames, IA 50010, USA 
(TNHC); the University of Michigan Museum of Zoology (UMMZ); the Division of Amphibians and Reptiles, National Museum of Natural History (USNM); the Amphibian and Reptile Diversity Research Center at the University of Texas at Arlington (UTA); the University of Texas at El Paso (UTEP); the University of Washington Burke Museum (UWBM); and the Yale Peabody Museum (YPM).

Publisher's Note Springer Nature remains neutral with regard to jurisdictional claims in published maps and institutional affiliations. 